\title{
Studies on Transmission Network Planning Methods with the Comprehensive Effect of Uncertain Factors
}

\author{
Li hua $^{1, a}$, Jin shixin ${ }^{2, b}$,Li wei ${ }^{3, c}$, Zhang zixin 1, Zhao Lin ${ }^{1}$ \\ ${ }^{1}$ State Grid Liaoning Electric Power Company Limited Economic Research Institute, Shenyang, \\ China \\ ${ }^{2}$ State Grid Liaoning Electric Power Research Institute, Shenyang, China \\ ${ }^{3}$ People's Liberation Army 96630 troop, Beijing, China \\ adwghlih@163.com, ${ }^{\mathrm{b}} \mathrm{j}$ sxmumu@126.com, ${ }^{\mathrm{c}}$ fnfozv@163.com
}

Keywords: Uncertain Factors. Wind Power. Load. Network Planning.

Abstract. The uncertainty of wind power, illustrates that the uncertainty of load and wind power have a great impact on the transmission network planning results. In order to obtain more stable and reasonable plan, the transmission network planning which considering the combined effect of wind power and load is studied in this paper. In order to consider the combined uncertainty of wind power and load, through the analysis of the annual load data and the wind power data, this paper proposes a transmission network planning method considering the combined effect of wind power and load. The examples show that by using the proposed model we can get the more robust and more effective planning scheme. In short, the transmission planning method considering the comprehensive effect of wind power in this paper will provide a new thought for the effective utilization of wind power.

\section{Introduction}

The scientific and rational expansion planning of transmission network system can contribute effectively to accept large-scale wind power. Hence need to research new approach differ from traditional planning methods for the characteristics of the wind farm, to accommodate wind farms and network transmission requirements. Meanwhile, the power system operation also has other uncertainties, particularly load fluctuations; there is some interaction with the random fluctuations of wind power. Thus, considering combined effect of wind power and load is very necessary.

In short, considering the uncertainty of load and wind power in transmission network planning, in order to build a reasonable structure, and increase flexibility, economy, security.

\section{Trend Analysis of Wind Power Fluctuations}

\section{A. Wind power model}

The wind speed variation mostly obeys the Weibull distribution, it can be described use form factor $\mathrm{k}$ and scale factor $\mathrm{c}$, the distribution function of wind speed $\mathrm{V}$ is:

$$
\mathrm{F}(\mathrm{v})=1-\mathrm{e}^{-\left(\frac{\mathrm{v}}{\mathrm{c}}\right)^{\mathrm{k}}} \quad F(\mathrm{v})=1-\mathrm{e}^{-\left(\frac{\mathrm{v}}{\mathrm{c}}\right)^{\mathrm{k}}}
$$

Among them, the wind speed $\mathrm{v}$ Introduction density function is:

$$
f(v)=\frac{k}{c}\left(\frac{v}{c}\right)^{k-1} e^{-\left(\frac{v}{c}\right)^{k}}
$$

The relationship between output power $\mathrm{P}$ of wind generator and the wind speed can be expressed as:

$$
\mathrm{P}= \begin{cases}0 & \mathrm{v}<\mathrm{v}_{\text {in }} \text { 或 } \mathrm{v}>\mathrm{v}_{\text {out }} \\ \mathrm{P}_{\mathrm{r}} \frac{\mathrm{v}-\mathrm{v}_{\text {in }}}{\mathrm{v}_{\text {rate }}-\mathrm{v}_{\text {in }}} & \mathrm{v}_{\text {in }} \leq \mathrm{v}<\mathrm{v}_{\text {rate }} \\ \mathrm{P}_{\text {rate }} & \mathrm{v}_{\text {rate }} \leq \mathrm{v}<\mathrm{v}_{\text {out }}\end{cases}
$$

In the above formula: $\mathrm{P}$ is output power (MW), $\mathrm{Pr}$ is rated output power, $\mathrm{v}_{\text {rate }}$ is rated wind speed of rated output power, $v_{\text {in }}$ is the size of the cut-in speed $(\mathrm{m} / \mathrm{s}), \mathrm{v}_{\text {out }}$ is the size of the cut-out wind 
speed $(\mathrm{m} / \mathrm{s})$. Since the wind speed has been changing over time, the output of the fan is ready to fluctuations; this uncertain distribution will have a huge impact on system flow distribution.

B. DC power flow model

DC power flow model of Power System is:

$$
P=B \theta
$$

Where: $\mathrm{P}$ is injected power vectors of node; $\mathrm{B}$ is the imaginary part of the node admittance matrix, $\theta$ is the phase angle vector of node voltage.

$$
\theta=B^{-1} P=X P
$$

Where $\mathrm{X}$ is the reactance matrix of node.

The voltage phase angle allows you to determine the line trend; the expression of the branch trend is as follows:

$$
\mathrm{P}_{\mathrm{ij}}=\left(\theta_{\mathrm{i}}-\theta_{\mathrm{j}}\right) / \mathrm{x}_{\mathrm{ij}}
$$

Where: $\mathrm{i}, \mathrm{j}$ represent different node number, $\mathrm{P}_{\mathrm{ij}}$ represents the size of the power on branch $\mathrm{ij}, \theta_{\mathrm{i}}, \theta_{\mathrm{j}}$ represent the phase angle of nodes $\mathrm{i}, \mathrm{j}, \mathrm{x}_{\mathrm{ij}}$ represents the line e reactance between nodes $\mathrm{i}$ and $\mathrm{j}$.

The vector representation of the formula as the following formula:

$$
P_{l}=B_{l} \phi
$$

Where: $P_{1}$ is lines flow vector in the system; $\phi$ is the difference vector of phase angle between line ends; $B_{1}$ is a diagonal matrix consisting of each branch admittance.

Solving expression of phase angle difference vector $\phi$ of both ends of the branches as follows:

$$
\phi=A^{T} \theta
$$

In the above formula $A^{T}$ represents a transpose of node branch incidence matrix, so far, it has been the relationship between line trend and the node injection power:

$$
P_{l}=B_{l} A^{T} B^{-1} P
$$

If the node power variations caused by wind power integration is expressed as $\Delta P_{w}$, the whole system flow power line fluctuations caused by wind changes can be expressed as:

$$
\Delta P_{l}=B_{l} A^{T} B^{-1} \Delta P_{w}
$$

In order to reflect the operation of line trend caused by wind added, definite system line run severity here:

$$
\mathrm{u}=\sum\left[\left(P_{d}+\Delta P_{l}\right) / P_{\max }\right]
$$

Where $\mathrm{u}$ represents the sum of system each line trend and the ratio of the line capacity maximum, $\mathrm{P}_{\mathrm{d}}$ is the flow vector of each branch in the absence of wind power access, $\mathrm{P}_{\max }$ is the vector of maximum capacity of each line.

\section{Analysis on Fluctuation of wind power and load}

\section{A. Curve generation}

According to the parameters provided by the IEEE-RTS. Annual each hour average load used by annual load duration curve expressed as:

Where:

$$
L(t)=L_{y} \times P_{w k} \times P_{d} \times P_{h}(t)
$$

$\mathrm{L}_{\mathrm{y}}$----peak load

$\mathrm{P}_{\mathrm{wk}} \mathrm{C}^{---} 52$ weeks average peak load percentage of annual peak load

$P_{d}$---- Daily average peak load percentage of the week peak load

$\mathrm{P}_{\mathrm{h}}(\mathrm{t})$---- 24 hours average peak load in a day percentage of daily peak load

Therefore, as long as that annual load peak load of forecast year, it can base on the formula (12), calculated load data of each hour within a year, getting the timing load curve.

B. Scene extraction method based on Annual load and annual wind power output

Since each hour take a scene, the number of the scene will reach 8,760, which wo uld greatly increase the amount of system computation. Considering system operating conditions will be more demanding under the circumstances that load or wind power output is greater, so the selection process is typically given in this article. Selection step of typical scenario is as follows: 
(1) Select P states own arge wind power out of the total 8760 scene, composed P scenes with then load.

(2) Similarly, Select Q states own arge load out of the total 8760 scene.

According to the analysis above the typical time wind data and load data, the point of maximum 365 points each time under the load point of maximum output of wind power as a typical moment of scene, you can select $\mathrm{M}$ scene from 24 time, saving the computation.

\section{Transmission network planning considerations combined effect of wind and load}

A. Transmission network planning model

Large-scale wind power into the power grid, establish a flexible programming model of transmission network considering the combined effect of the uncertainty of wind power and load:

$$
\min Z=C(X)+C_{N-1}(X)
$$

s.t.

$$
\begin{gathered}
\left\{\begin{array}{cc}
\sum_{\forall i \in N_{g k}} G_{i}^{n}-L_{k}^{n}=\sum_{\forall i \in N_{i k}} P_{i}^{n} k=1, \ldots, N_{b} \\
P_{i}^{n}=B_{i}^{n}\left(\theta_{k}^{n}-\theta_{l}^{n}\right) \\
G_{\operatorname{mini}} \leq G_{i}^{n} \leq G_{\max i} & i=1, \ldots, N_{g} \\
-P_{\operatorname{maxi}} \leq P_{i}^{n} \leq P_{\operatorname{maxi}} \quad & i=1, \ldots, N_{l}
\end{array}\right. \\
\left\{\begin{array}{c}
\sum_{\forall i \in N_{g k}} G_{i}^{n}-L_{k}^{n}=\varepsilon_{i}^{n} \quad k=1, \ldots, N_{h} \\
P_{i}^{n(j)}=B_{i}^{n(j)}\left(\theta_{k}^{n(j)}-\theta_{l}^{n(j)}\right) \\
G_{\operatorname{mini}} \leq G_{i}^{n} \leq G_{\max i} \quad i=1, \ldots, N_{g} \\
-P_{\text {maxi }} \leq P_{i}^{n}(j) \leq P_{\max i} \quad i=1, \ldots, N_{l} \\
\sum_{j=1}^{N} q^{j} P_{r}^{j}\left\{\left(\left|P_{b}^{j}\left(\varepsilon^{n}\right)\right|>P_{b . \max }\right) / X\right\} / \sum_{j=1}^{N} q^{j} \leq \beta
\end{array}\right.
\end{gathered}
$$

Wherein $X$ is a plan whose elements are made of 0 and 1,0 represents this line is not selected, 1 represents link is selected; $\mathrm{C}(\mathrm{X})$ represents the cost of the new line required; $\mathrm{C}_{\mathrm{N}-1}(\mathrm{X})$ is penalty term of system whole circuit overload when N-1 fault off; formula (14) is the security constraints of normal operation; formula (15) is state safety restriction for the $\mathrm{N}-1$ static. $\mathrm{N}$ represents the number of different wind loads scene, $G_{i}^{n}$ is the the generation(MW) of $i$-th generator at the scene $n, B_{i}^{n}$ and $B_{i}^{n(j)}$ is the node admittance matrix, respectively normal operating conditions and branch $j$ breaking way; in $P_{i}^{n}$ and $P_{i}^{n}(j)$ are power vectors (MW) of two ways on the line $i$; $L_{k}^{n}$ is load power(MW) on node $\mathrm{k}$ when the scene is $\mathrm{n} ; \theta_{\mathrm{k}}^{\mathrm{n}}$ and $\theta_{\mathrm{k}}^{\mathrm{n}(\mathrm{j})}$ are the the voltage phase angle; $\mathrm{N}_{\mathrm{g}}$ represents the total number of generators; $\mathrm{N}_{\mathrm{gk}}$ represents generator set of node $\mathrm{k} ; \mathrm{N}_{\mathrm{l}}$ is the total number of original line and selected line; $\mathrm{N}_{\mathrm{b}}$ represents the total number of nodes.

B. Cases Operators

As shown in Figure 1, 18-node system simulation. Node 1 to 10 is the original system nodes, 11 to 18 is the new power supply and the load node.

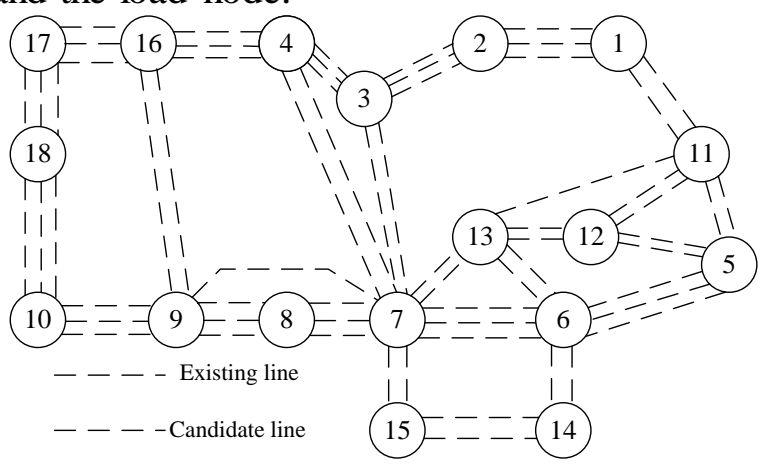

Figure 1. Node system architecture diagram.

The do integration process on wind data and the annual load data, according to the above scenario extraction and extract all of the extreme scenarios, calculated different planning to meet different safety requirements for systems. 
Table 1. Program considering wind and load.

\begin{tabular}{|c|c|c|c|}
\hline Program 4 & \multicolumn{2}{|c|}{ Program 5} & Program 6 \\
\hline$\beta=0$ & \multicolumn{2}{|c|}{$\beta=0.1$} & $\beta=0.2$ \\
\hline $\begin{array}{c}1-11,4-16,5-11,5-12,6-13,6-14,7-13,7-15,8-9(2), 9-1 \\
0,9-16,10-18(2) \\
11-12,12-13,14-15(2), 16-17,17-18(3)\end{array}$ & \multicolumn{2}{|c|}{$\begin{array}{l}1-11,4-16,5-12 \\
-13(2), 7-15,8-9(2), 9-10,9-16 \\
1-12,14-15,16-17,17-18(2)\end{array}$} & $\begin{array}{c}1-11,4-16,5-12, \\
6-7,6-13,6-14,7-15,8- \\
9,9-10,10-18 \\
11-12,12-13,14-15 \\
16-17,17-18\end{array}$ \\
\hline \multicolumn{4}{|c|}{ Table 2. Comparison of program. } \\
\hline Project & Program4 & Program5 & Program6 \\
\hline Number of lines & 22 & 18 & 15 \\
\hline Line length/km & 2195 & 1782 & 1520 \\
\hline Overload costs/Ten thousand yuan & 0 & 2430 & 3833 \\
\hline Total cost/Ten thousand yuan & 175450 & 146273 & 124880 \\
\hline
\end{tabular}

In the case of access to large-scale wind power, planning in the maximum load was maintained at a very short time, if in order to meet the shorter peak load to use the most stringent plan, not only will make the total investment considerably large, but also the construction line is low in order to cope with peak load. If the overload allowable amount is too large it will make the system's security is threatened, so in order to balance the economy and security, should allow part of the system overload occurs, then the program should select five reference solutions. So when there is overload, it is possible to eliminate the overload, to ensure safe and reliable operation of the system by adjusting the generator output or demand side response implementation.

\section{Conclusions}

By the combined uncertainty effect of wind power and load paper analyzes the annual load curves and wind power curve, proposed a transmission network planning model considering the combined effect of wind and load. In the model, through the analysis of the typical of the time characteristics to form typical scenes of the entire year. By analyzing the combined effect impact considering of wind and load on the planning result, and to do a comparison with plan only considers wind power fluctuations and find that planning results considering combined effect of wind power and load is better than only consider wind power fluctuations. In addition, by setting different probabilities AM overload available to meet different requirements of grid security plan, in order to balance economic and security of planning programs. The example shows that the proposed model may get more robust, cost-effective plan.

\section{References}

[1] RICHARD P, DALE O. Wind Energy Delivery Issues [J].IEEE Power \& Energy Magazine, 2005, 03(6): 47-56.

[2] MARTIN P S, RAMOS A, ALONSO J F. Probabilistic midterm transmission planning in a liberalized market [J]. IEEE Trans on Power Systems, 2005, 20(4):2135-2142.

[3] CORBUS D, LEW D, JORDAN G, et al. Up with Wind [J].IEEE Power and Energy Magazine, 2009,07(6): 36-46.

[4] Pedro S M, An bal TA. Multi-objective optimization of a mixed renewable system with demand-side management[J]. Renewable and Sustainable Energy Reviews, 2010(14): 1461-1468.

[5] Hamidi V,Li F, Robinson F. Responsive demand in networks with high penetration of wind power[C] .Transmission and Distribution Conference and Exposition, 2008: 1-7.

[6] Al-Alawi A,Islam S M. Demand side management for remote area power supply systems incorporating solar irradiance model [J]. Renewable Energy, 2004, 29(13): 2027-2036. 